\title{
A REALIDADE DO TRABALHO DO PROFESSOR DO ENSINO SUPERIOR: PESQUISA BIBLIOGRÁFICA ON-LINE EM FOCO
}

\author{
Zelina Cardoso Grund, Renata Portela Rinaldi \\ Universidade Estadual Paulista - UNESP, Presidente Prudente, SP. E-mail: zelina2509@terra.com.br, \\ renata.rinaldi@unesp.br
}

\section{RESUMO}

O presente artigo tem como objetivo apresentar o levantamento das produções acadêmicas sobre "formação de professores e trabalho docente" no ensino superior, produzidas no período de 2007 a 2017 e publicadas pela Associação Nacional de Política e Administração da Educação (ANPAE). A metodologia utilizada foi a pesquisa bibliográfica on-line a partir de parâmetros criteriosamente definidos com o objetivo de apoiar um estudo mais amplo sobre o "estado do conhecimento". Foram utilizados os seguintes descritores: formação de professores, trabalho docente, ensino superior. Selecionamos os trabalhos completos do banco de dados do Congresso Ibero-Americano de Política e Administração Escolar e do Simpósio Brasileiro de Política e Administração Escolar. O tratamento e análise das informações foi sistematizado a partir de um protocolo de análise bibliográfica. O resultado evidencia que há um número reduzido de publicações sobre o tema no eixo pertinente à educação superior nos eventos científicos tanto nacionais quanto internacionais. Palavras-chave: Formação de professor. Trabalho docente. Ensino superior.

\section{THE REALITY OF THE WORK OF PROFESSOR OF HIGHER EDUCATION: BIBLIOGRAPHICAL RESEARCH ONLINE AT FOCUS}

\begin{abstract}
This article aims to present the survey of academic production on "teacher training and teaching work" in higher education, produced in the period from 2007 to 2017 and published by the National Association of politics and administration of Education (ANPAE). The methodology used was bibliographical research online from carefully defined parameters in order to support a broader study on the "State of knowledge". The following descriptors were used: teacher training, teaching, higher education work. Select the complete works of the Ibero-American Congress of policy and school administration and the Brazilian Symposium of politics and Administration. The treatment and analysis of the information was systematized from a bibliographical analysis protocol. The result shows that there are a small number of publications on the subject in the relevant axis to higher education in national and international scientific events.
\end{abstract}

Keywords: Training of teacher. Teaching work. Higher education. 


\section{INTRODUÇÃO}

Atualmente, o mundo tem sido moldado pelas tendências da globalização, em especial do avanço tecnológico, cujas mudanças influenciam diversos aspectos da vida em sociedade e repercutem também nos processos de formação profissional. Notadamente, na profissão docente o panorama também é de transformação profunda. Segundo Nóvoa (1999, p. 15) "A gênese da profissão de professor tem lugar no seio de algumas congregações religiosas, que se transformaram em verdadeiras congregações docentes". Passou a ser considerado um ofício, sujeito a autorização para o exercício do trabalho, efetivando-se a criação de instituições de formação com a conquista das escolas normais, preparando o professor para a profissionalização da atividade docente.

$\mathrm{Na}$ contemporaneidade, no Brasil, a formação profissional dos professores preferencialmente deve ser realizada em nível superior e, segundo Nóvoa (2009, p. 12):

Os professores reaparecem, neste início do século XXI, como elementos insubstituíveis não só na promoção das aprendizagens, mas também na construção de processos de inclusão que respondam aos desafios da diversidade e no desenvolvimento de métodos apropriados de utilização das novas tecnologias.

Nesse cenário, nos propusemos a compreender, a partir da revisão de literatura, como a formação de professores e o trabalho docente no ensino superior têm comparecido nas pesquisas científicas nas bases de dados da Associação Nacional de Política e Administração da Educação (ANPAE).

\section{PERCURSO METODOLÓGICO}

A metodologia utilizada foi a pesquisa bibliográfica on-line a partir de parâmetros criteriosamente definidos com o objetivo de apoiar um estudo mais amplo sobre o "estado do conhecimento". Para isso adotou-se três procedimentos, a saber: primeiramente, fez-se o levantamento bibliográfico de trabalhos completos no banco de dados do Congresso IberoAmericano de Política e Administração Escolar e do Simpósio Brasileiro de Política e Administração Escolar, a partir das palavras-chave: formação de professores, trabalho docente, ensino superior; posteriormente, utilizou-se um protocolo de análise bibliográfica que serviu de suporte para fazer análise geral dos resultados, de acordo com: temática; problema; objetivos; abordagem e procedimentos metodológicos;

participantes e referencial do estudo mapeado; abordagem do estudo descritivo; resultados obtidos e principais referências do estudo mapeado. Por fim, elaborou-se relatório descritivo analítico qualiquantitativo da pesquisa, o qual serviu de instrumento para a proposta do presente artigo.

\section{APRESENTAÇÃO DOS RESULTADOS}

Alguns resultados gerais do Congresso Ibero-Americano de Política e Administração Escolar

A cada evento é apresentado um tema central, no qual se integram os subtemas, por sessões e Eixos temáticos de discussão. Na oportunidade da pesquisa não foram encontradas as publicações do I Congresso Ibero-Americano, realizado em 2010 na Espanha, assim como do II Congresso que foi realizado conjuntamente com o XXV Simpósio Brasileiro de Política e Administração Escolar, em 2011.

No ano de 2012 foi realizado o III Congresso Ibero-Americano cujo tema central foi "Gestão Pedagógica e Política Educacional: desafios para a melhoria da formação e profissionalização dos educadores". Os trabalhos foram divididos em oito eixos temáticos, dos quais foram identificadas publicações sobre o tema investigado apenas no Eixo 3, intitulado "O papel da universidade na 
formação dos profissionais da educação para a qualidade e a inovação educacional" com um total de $28^{1}$ trabalhos publicados.

No IV Congresso Ibero-Americano (2014) o tema central foi "Políticas e práticas de Administração e Avaliação na Educação Ibero-Americana", os trabalhos foram distribuídos em 06 (seis) eixos temáticos, dos quais o eixo 2 versava sobre a Educação superior e intitulava-se "Gestão e avaliação da educação superior" e foram publicados 50 trabalhos. Nos V Congresso IberoAmericano, realizado em 2016, o tema central foi "Política e Gestão da Educação: Discursos Globais e Práticas Docentes". Na leitura dos artigos publicados nos eixos 1, 3, 4, 5, 6 e 7 observouse que os assuntos variavam entre organização curricular, inclusão, diversidade cultural, inclusão social, avaliação, planejamento, financiamento. No eixo 2, cujo tema foi "Política e gestão da Educação Superior" houveram 24 trabalhos publicados.

\section{Alguns resultados gerais do Simpósio Brasileiro de Política e Administração Escolar}

$\mathrm{Na}$ análise dos textos publicados nos Simpósios Brasileiros de Política e Administração Escolar, devido a organização e disponibilidade das produções, optou-se por realizar o levantamento bibliográfico a partir das três grandes temáticas que poderiam se articular ao estudo: trabalho docente (13 artigos); formação continuada em serviço (9 artigos); políticas públicas educacionais ( 2 artigos). A primeira e segunda temáticas se integram à maioria dos temas dos eventos. A terceira, de alguma maneira, versa sobre a formação e o trabalho docente.

No caso das duas primeiras temáticas nos deparamos com duas investigações sobre o trabalho docente: uma versava sobre a avaliação por resultados em universidades, que exige dos professores universitários a produtividade, provocando o mal-estar devido a intensificação e a precarização do trabalho docente; a outra sobre a sensação de desamparo que sente o professor no seu ambiente de trabalho, em relação à pesquisa, à docência propriamente dita, à sujeição aos mecanismos de regulação pelas universidades. A contratação de professores colaboradores é frequente nas universidades com a finalidade de reduzir o quadro de profissionais concursados. Outro ponto, de destaque abrange a avaliação do trabalho do professor universitário com base na quantificação das publicações realizadas pelos docentes, de preferência em periódicos indexados, especialmente internacionais. As práticas de ensino com o uso da tecnologia foram apresentadas como estratégias e recursos metodológicos, viabilizando outras formas de interação entre professor/aluno e a mediação sobre os conteúdos de ensino.

A ética profissional do docente universitário nas suas relações, práticas, qualidade do trabalho, no diálogo, na formação permanente, também compareceu nas produções. A necessidade de rever o modo de ensinar do professor universitário foi abordada em um estudo que teve como objetivo estudar os processos de profissionalização de professores que atuam no ensino superior.

Quanto as políticas públicas educacionais, verificou-se que a legislação trazida à luz da interpretação, quando analisados os aspectos jurídicos apresentam influência na vida do professor. É possível detectar na produção acadêmica referências ao sistema mercantilista, quando da imposição por parte de algumas universidades à prestação de serviços a terceiros e intensificação do trabalho do professor. O procedimento alerta para as reformas na educação, na visão mercantilista de um Estado, que segundo Frigotto, (2010, p. 67) caracteriza-se como "exploração capitalista".

\section{DISCUSSÃO DOS RESULTADOS}

No que tange ao total de trabalhos selecionados nos Congressos Ibero-Americanos, segundo os descritores, identificou-se que a formação do professor só apareceu nas publicações

\footnotetext{
${ }^{1}$ É importante esclarecer que todos os trabalhos tiveram os títulos analisados para se verificar que apenas no eixo relativo ao ensino superior haviam produções sobre o nível de ensino.
} 
do ano de 2012, enquanto aquelas sobre o trabalho docente se apresentaram nos anos de 2014 e 2016, conforme tabela 1.

Tabela 1. Total de trabalhos selecionados na base de dados nos Congressos Ibero-Americanos

\begin{tabular}{llllll}
\hline Ano & $\begin{array}{l}\text { Número de } \\
\text { trabalhos } \\
\text { Consultados }\end{array}$ & $\begin{array}{l}\text { Número } \\
\text { trabalhos } \\
\text { Selecionados }\end{array}$ & de & $\begin{array}{l}\text { Formação } \\
\text { Professor }\end{array}$ & $\begin{array}{l}\text { Trabalho } \\
\text { Docente }\end{array}$ \\
\hline 2012 & 28 & 3 & 10,7 & 3 & 0 \\
2014 & 80 & 3 & 3,7 & 0 & 3 \\
2016 & 22 & 1 & 4,5 & 0 & 1 \\
Total & 130 & 7 & & 3 & 4 \\
\hline
\end{tabular}

Fonte: Organizado pelas autoras a partir do banco dedados da Associação Nacional de Política e Administração da Educação (ANPAE).

Verifica-se na tabela acima, que o número de 03 publicações em 2012 está equiparado ao de 2014, superando 2016, que apresentou apenas 01 trabalho. Porém, levando em conta os números totais de trabalhos consultados, proporcionalmente, aos seus correspondentes percentuais, nota-se que os eventos de 2014 ( 80 trabalhos) com apenas 03 selecionados perfazem apenas 3,7\%, enquanto que 2012 (28 trabalhos) com 03 selecionados perfazem $10,7 \%$. Quanto a 2016 (22 trabalhos) com 01 selecionado representa 4,5\%.

$\mathrm{Na}$ distribuição dos trabalhos por regiões percebe-se como é tímida a participação das mesmas, de acordo com a tabela 2.

Tabela 2. Distribuição de trabalhos nos Congressos Ibero-Americanos por região geoeconômica brasileira.

\begin{tabular}{lllll}
\hline Norte & Nordeste & Centro-Oeste & Sudeste & Sul \\
\hline 2 & 1 & 1 & 2 & 1 \\
\hline
\end{tabular}

Fonte: Organizado pelas autoras a partir do banco dedados da Associação Nacional de Política e Administração da Educação (ANPAE).

Pelos dados da tabela 2, não há uma discrepância entre uma e outra região, pois o número de publicações quase que se equipara, demonstrando o baixo interesse pela temática nesse evento por parte dos pesquisadores em investigar a formação de professor e trabalho docente no ensino superior. Ainda foi possível averiguar que as publicações se vincularam a 4 universidades federais, 1 estadual e 4 particulares, assim distribuídas com o respectivo total de publicações: URI - Universidade Regional do Alto Uruguai e das Missões - Campus de Frederico Westphalen, RS com 1 publicação; FDV - Faculdade de Direito de Vitória, Espirito Santo (1 artigo); UNIMONTES Universidade Estadual de Montes Claros, Minas Gerais (1 artigo); UFU - Universidade Federal de Uberlândia, Minas Gerais (1 artigo); UDF - Centro Universitário do Distrito Federal, Brasília, Brasil (1 artigo); IFPA - Instituto Federal de Educação, Ciências e Tecnologia do Pará (1 artigo); ULBRA Universidade Luterana do Brasil, Pará (1); UFBP - Universidade Federal da Paraíba, PB (1); e a UFPA - Universidade Federal do Pará, Pará (1).

De modo geral percebemos que as discussões mais recorrentes voltaram-se para temas como: avaliação, extensão, diversificação e flexibilização (6 trabalhos); os processos de expansão, estágio e qualificação (5 trabalhos); políticas da educação superior (3 trabalhos); o papel da universidade na formação de pedagogos ( 3 trabalhos). Os demais trabalhos são identificados como: programas institucionais (PROUNI, PIBID); a inserção da EAD nos cursos presenciais; avaliação dos cursos de mestrado e doutorado, matrículas no ensino superior e outras. Além disso, evidenciaram-se nos trabalhos: a falta de autonomia, tanto por parte dos docentes do ensino 
superior como pela universidade; o mal-estar no trabalho sob a influência do Estado, dada a cobrança sistemática; a institucionalização e a profissionalização que se encontram nas publicações de maneira generalizada; as políticas públicas sob a forma da análise da legislação são mencionadas em alguns artigos; a formação do docente do ensino superior. Este último, embora tenha um papel relevante na universidade, tem se apresentado de forma retraída, pois, pelo levantamento de dados o tema não é recorrente. Os autores se concentraram mais no desenvolvimento de pesquisa bibliográfica ( 4 trabalhos) e documental ( 4 trabalhos) e estudo de caso (6 trabalhos).

No total de trabalhos selecionados nos Simpósios Brasileiros de Política e Administração Escolar, foi possível verificar na tabela 3 que o número de publicações sobre trabalho docente e formação continuada para professores do ensino superior oscilaram muito entre os anos.

Tabela 3. Total de trabalhos selecionados na base de dados nos Simpósios Brasileiros de Política e Administração Escolar segundo os descritores

\begin{tabular}{llllllll}
\hline Ano & $\begin{array}{l}\text { Número de } \\
\text { trabalhos } \\
\text { Consultados }\end{array}$ & $\begin{array}{l}\text { Número de } \\
\text { trabalhos } \\
\text { Selecionados }\end{array}$ & & $\begin{array}{l}\text { Formação } \\
\text { Professor }\end{array}$ & $\begin{array}{l}\text { Trabalho } \\
\text { Docente }\end{array}$ & $\begin{array}{l}\text { Políticas } \\
\text { Públicas }\end{array}$ \\
\hline 2007 & 57 & 9 & 15,7 & 3 & 5 & 1 \\
2009 & 384 & 5 & 1,3 & 2 & 3 & 0 \\
2011 & 553 & 6 & 1,1 & 3 & 3 & 0 \\
2013 & 31 & 1 & 3,2 & & 0 & 1 & 0 \\
2015 & 64 & 3 & 4,7 & 1 & & 1 & 1 \\
Total & 1.089 & 24 & & 9 & & 13 & 2 \\
\hline
\end{tabular}

Fonte: Organizado pelas autoras a partir do banco dedados da Associação Nacional de Política e Administração da Educação (ANPAE).

Conforme a tabela 3, em 2009 e 2011, de 384 e 553 trabalhos consultados nesses anos, respectivamente, o número de trabalhos selecionados de 5 e 6 são muito baixos, em relação a 2007, 2013 e 2015. Na performance das universidades participantes dos Simpósios observamos que todas as regiões participaram dos eventos. No caso da Região Sul, o Estado do Rio Grande do Sul teve uma maior representatividade, pois dos 16 trabalhos apresentados, 12 concentraram-se neste estado, sendo 5 universidades federais com 7 trabalhos; comunitária (1 trabalho), 3 universidades privadas com a proposição de 4 trabalhos. Os demais trabalhos (4) foram do estado do Paraná. A explicação para o número elevado de trabalhos pode ser pela extensão das universidades federais criadas a partir de 2003, vindo a possibilitar a participação dos Campus Universitários nos eventos científicos.

Quanto a metodologia aplicada pelos autores na pesquisa, percebeu-se que a mesma não é identificada em grande parte dos trabalhos, tanto no resumo como no artigo completo. Daqueles em que se verificou, observamos a recorrência de 3 estudos de casos, 1 com história de vida e 1 investigação narrativa e algumas pesquisas de cunho bibliográfico e documental, mencionados de maneira clara pelos autores. Em alguns casos aparecem alguns equívocos, como a menção de apenas pesquisa bibliográfica e documental, quando percebe-se na leitura do artigo completo todo o procedimento de um estudo de caso ou de pesquisa-ação.

No final da pesquisa observaram-se temáticas recorrentes como: a necessidade da construção da competência pedagógica aos professores universitários que não possuem tal formação; a inclusão da tecnologia e a capacitação do docente para o uso do ambiente virtual no trabalho; a dispensa da carga horária para orientação de estágio aos discentes; a intensificação da produção acadêmica; a imposição de sobrecarga de trabalho, tendo em vista a necessidade de ter de substituir o colega afastado, temporariamente, ou aposentado. Na pesquisa os programas 
de formação continuada aparecem de maneira um pouco tímida, o que indica a necessidade de mudanças nos procedimentos administrativos e pedagógicos no ensino superior.

\section{CONSIDERAÇÕES FINAIS}

Para a elaboração do trabalho foi necessário proceder a leitura dos textos completos, pois alguns resumos não forneciam os elementos necessários para a efetivação da análise. Outros ficaram só no campo da reflexão, sem a problemática, o objetivo, a metodologia e o resultado final da pesquisa. Em 11 (onze) publicações não aparece a metodologia no resumo do artigo completo, ou seja, está "ausente". Há três estudos de casos, uma história de vida e uma investigação narrativa e algumas pesquisas de cunho bibliográfico e documental, mencionados de maneira clara pelos autores. Em alguns casos aparecem alguns equívocos, como a menção de apenas pesquisa bibliográfica e documental, quando no artigo completo há todo o procedimento de um estudo de caso ou de pesquisa-ação. Por outro lado, há situações em que há informações precisas, a exemplo da menção ao referencial teórico e os autores relacionados ao mesmo.

Os dados apontados, em parte, foram resultado da oportunidade dos pesquisadores ouvirem os professores e professoras, que deixaram transparecer as suas vivências no papel de docentes universitários, identificadas nas pesquisas realizadas por meio de estudo de caso ou pesquisa-ação. Diante desse quadro, há de se admitir que as mudanças mais recentes introduzidas nas universidades têm provocado um processo de intensificação e precarização do trabalho docente, o que implica muitas vezes no adoecimento dos docentes e até mesmo no pedido de exoneração do servidor público. Tais mudanças, de certa forma levam a "desconstrução do trabalho sem precedentes em toda era moderna" (ANTUNES, 2015, p. 259), prejudicando a formação em serviço.

\section{REFERÊNCIAS}

ANTUNES, R. Adeus ao trabalho. 16. ed. São Paulo: Cortez, 2015.

ANPAE -Associação Nacional de Política e Administração da Educação. Disponível em: http://www.anpae.org.br/website/publicacoes/biblioteca-anpae. Acesso em: 03 abr. 2017.

FRIGOTTO, G. São Paulo: Cortez, 2010. Educação e a crise do Capitalismo. São Paulo: Cortez, 2010.

PARANÁ. Lei n. 11.500 , de 5 de agosto de 1996. Autoriza as IES a prestarem serviços e/ou produzirem bens para terceiros, bem como repassarem aos servidores, parte da receita decorrente, conforme Disponível em: www.legislacao.pr.gov.br/legislacao/listarAtosAno.do?action=exibir\&codAto=3883. Acesso em: 30 jun. 2018. 